\title{
THE CORRECTED TWO-POINT WEIGHTED \\ QUADRATURE FORMULAE
}

\begin{abstract}
SANJA KOVAČ
Abstract. We derive a corrected version of the weighted two-point quadrature formula, which provides a better approximation accuracy than the ordinary two-point quadrature formulae. In the corrected two-point formula the integral is approximated both with the values of the integrand in nodes $-x$ and $x$, and the values of its first derivative at the endpoints of the interval $[-1,1]$. The error estimates under various regularity conditions for such formulae are established. As special cases, the corrected two-point formulae of Gauss type are obtained. Also, corrected version of weighted trapezoid, midpoint, two-point Maclaurin and two-point Newton-Cotes formulae are considered.
\end{abstract}

Mathematics subject classification (2010): 26D15, 65D30, 65D32.

Keywords and phrases: weight function, corrected quadrature formula, two-point quadrature formula, $w$ - harmonic sequences of functions, $L_{p}$ spaces, corrected Gauss formula, weighted corrected Maclaurin formula, weighted corrected trapezoid formula, weighted corrected midpoint formula, weighted corrected Newton-Cotes two-point formula.

\section{REFERENCES}

[1] A. Guessab, G. SchmeIsser, Sharp integral inequalities of the Hermite-Hadamard type, Journal of Approximation Theory, 115, 2 (2002), 260-288.

[2] S. KOVAČ, J. PEČARIĆ, A. VuKELIĆ, A generalization of general two-point formula with applications in numerical integration, Nonlinear Analysis Series A: Theory, Methods and Applications, 68, 8 (2008), $2445-2463$.

[3] S. Kovač, J. PeČARIĆ, Weighted version of general integral formula, to appear in Math.Inequal.Appl.

[4] I. Franjić, I. Perić, J. PEČarić, Quadrature formulae of Gauss type based on Euler identities, Mathematical and Computer Modelling, 45, 3-4 (2007), 355-370.

[5] Lu. Dedić, M. Matić, J. PeČArić, On Euler trapezoid formulae, Applied Mathematics and Computation, 123 (2001), 37-62.

[6] Lu. Dedić, M. Matić, J. PeČArić, On Euler midpoint formulae, ANZIAM J, 46 (2005), 417-438.

[7] M. Matić, C.E.M. PeArCe, J. PeČARIĆ, Two-point formulae of Euler type, ANZIAM J, 44 (2002), 221-245. 